\title{
NC Machining of Special Geometry Part
}

\author{
Jingui Wan \\ Experimental Training Center, Shanghai Second Polytechnic University, Shanghai, China
}

\begin{abstract}
In order to study the NC machining technology of special geometry part, a dodecahedron part was trialmanufactured with CNC milling machine. First, the part was designed with UG software. Next, by analyzing the structural characteristics and requirements of the part, the process scheme was developed and the special fixture was designed. Then, with the CAM technology based on UG NX, the CNC programming was completed. Finally, the fixture and part were manufactured with a 3-axis CNC milling machine. The part was manufactured with high accuracy, meeting the technical requirements. The result shows that the process is reasonable and efficient. The integrated design and manufacture of the part with the special fixture is efficient, due to the powerful CAD/CAM function of UG. The method and technology introduced in this paper are useful for related study.
\end{abstract}

Keywords-NC machining; CAD/CAM; process analysis; special fixture; CNC programming

\section{INTRODUCTION}

With the rapid development of advanced manufacturing technology, modern industrial products are becoming more and more diverse and complex. Many of them have complex shape and high accuracy requirements, as in [1-3].These products are manufactured in modern manufacturing enterprises widely using $\mathrm{CNC}$ technology. It is very complicated for these products to be designed, molded, and produced in large quantities. And it is almost impossible to design and manufacture these products with manual methods. The application of $\mathrm{CAD} / \mathrm{CAM}$ technology has highlighted the tremendous role and advantages in modern advanced manufacturing ${ }^{[4]}$.

In recent years, many pieces of software supporting $\mathrm{CAD} / \mathrm{CAM}$ technology have been developed and widely used in current manufacturing industry. Unigraphics (UG) is one of the most popular software applied in NC machining. It has powerful modeling and automatic programming function. Furthermore, it achieves a seamless integration of $\mathrm{CAD} / \mathrm{CAE} / \mathrm{CAM}$ and is easy to use ${ }^{[5]}$. Therefore, $\mathrm{UG}$ is used in this study.

This paper studies the NC machining process and technology of a special geometry part, which is a dodecahedron. It includes three-dimensional (3D) modeling, process planning, a special auxiliary fixture designing and manufacturing, CNC programming, simulation and practical machining.

\section{DESCRIPTION AND 3D MODELING}

Here we received a group of production orders of a craft. The customer asked us to design and manufacture a real object calendar. A special geometry (dodecahedron) was designed, which had twelve surfaces and the numbers of date would be engraved on each surface, as shown in Figure I. First, a sample of this part should be trial-manufactured with CNC machine. Then, 800 parts like this would be produced in large quantities, made of aluminum alloy. Every surface of the craft was regular pentagon, and the length of each side was $35 \pm 0.02 \mathrm{~mm}$. The surface roughness was required to reach $\mathrm{Ra} 0.8 \mu \mathrm{m}$.

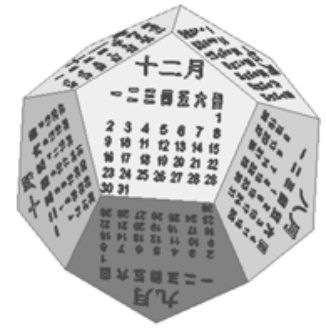

FIGURE I. THE DESIGN RESULT OF THE CRAFT

The part was designed in the modeling module of UG NX 8.0. The main design procedure of the dodecahedron is shown in Figure II (a) (e). It contains the following steps: (1) Drawing a regular pentagon in a sketch and changing it to a sheet. (2) Rotating copying the pentagon sheet along one side by a particular angle calculated by mathematical methods. (3) Instancing the other four pentagon sheets and sewing all the 6 sheets into one body. (4) Creating a correct datum plane and mirroring copying the body which was formed in last step. (5) Rotating the mirrored body by a particular angle and then uniting all the solid bodies into a single body.
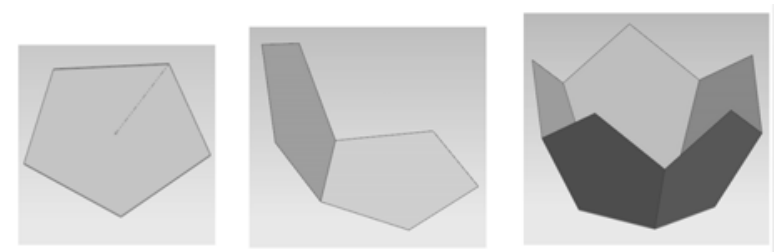

(a) A regular pentagon (b) Rotating copying one sheet (c) Instancing geometry

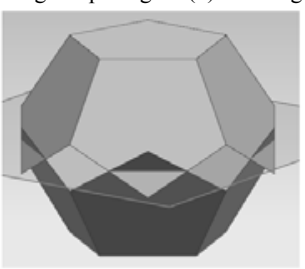

(d) Mirroring body

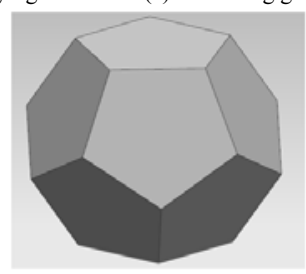

(e) Rotating body
FIGURE II. THE MODELING PROCESS OF THE PART (DODECAHEDRON)

After the dodecahedron was created, all the date numbers were written and typeset on every surface (see Figure I). 


\section{PROCESS ANALYSIS AND SCHEME}

According to the structural characteristics of the part, a cylindrical blank is suitable for processing it. Since the whole surface of the part needs to be machined, it should be fixed and clamped many times for machining. Limited to the production conditions and cost, this part would be machined with a 3 -axis CNC milling machine. Obviously, the part can't be simply clamped by universal fixture to complete all the processing. The machining sequence and clamping method of the part should be analyzed carefully to make the processing scheme. A special auxiliary fixture needs to be designed and manufactured in this work.

The processing scheme was determined as follows: (1) A cylindrical blank being clamped with a three-jaw chuck, the first half of the part will be rough and semi-finish machined. As shown in Figure III (a), the machining areas include six pentagon surfaces and a specially designed rectangular convex body (false boss). (2) Referring to Figure III (b), the IPW (in process workpiece) is turned upside down to machine the second half areas, the false boss being clamped with a plain vice. (3) A special auxiliary fixture is manufactured. (4) With the special fixture, the workpiece will be fixed and clamped twelve times to finish milling each pentagon surface and engrave the date numbers on it. In particular, the surface with the false boss must be machined first.

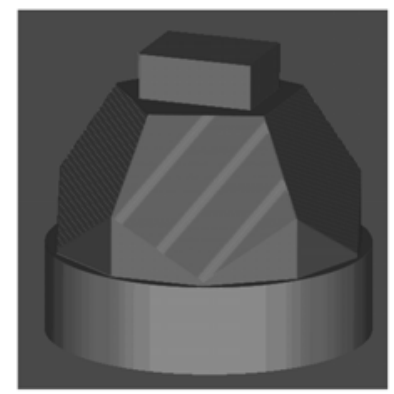

(a) Rough and semi-finish machining the first half

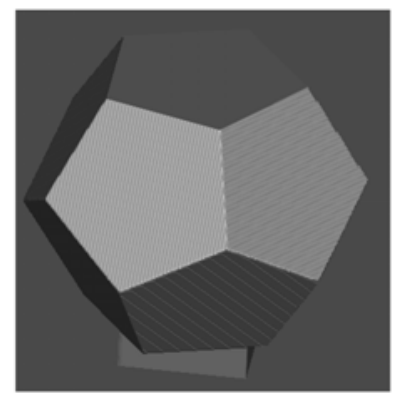

(b) Rough and semi-finish machining the second half

FIGURE III. THE SCHEMATIC DIAGRAM OF ROUGH AND SEMI-FINISH MACHINING THE PART

\section{Designing the Special FiXturee}

It is very important to design a proper special fixture for finish machining this part, especially for the mass production. The special fixture was designed as shown in Figure IV. (left). It contains two parts, which are the upper part and the lower part. In the modeling module of UG, the special fixture and the part were designed together, constituting the assembly model, as shown in Figure IV (middle and right). The workpiece can be positioned correctly in the lower part, while some adjustment measures should be taken to make the top surface level to be machined. Then the upper part is connected with the lower part by bolts, used to fix and clamp the workpiece during the finish machining. The special fixture can be clamped with a three-jaw chuck in $\mathrm{CNC}$ milling machine. And each surface of the dodecahedron can be installed at the same way to be machined.

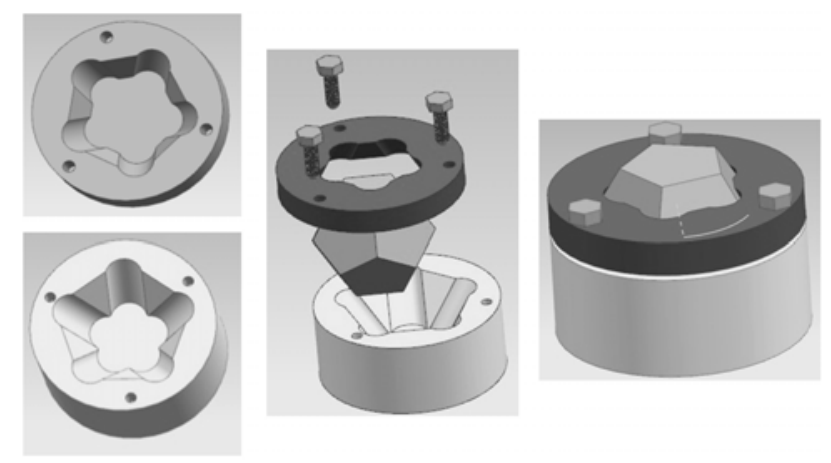

FIGURE IV. THE SPECIAL FIXTURE AND THE FIXING METHOD OF THE WORKPIECE IN THE FIXTURE

\section{CNC PROGRAMMING}

UG provides a powerful CNC programming function. After the $3 \mathrm{~d}$ model of the part and blank geometry (a cylinder of $\varnothing 100 \mathrm{~mm} \times 93 \mathrm{~mm}$ ) are created in the modeling module of UG, then we can enter the manufacturing module, initialize the machining environment, and perform $\mathrm{CNC}$ programming operation ${ }^{[6]}$. Here, the program groups, the tools, the geometries and the processing methods were created to form parent nodes, and then each machining operation was created based on them according to the machining process plan.

\section{A. Machining Process Planning}

According to the processing scheme stated above, the process plan of the part was made and shown in Table $I$.

\section{B. Machining Operation Creating, Tool Path Generating and Simulating}

All the machining operations of the part were created referring to Table I. The main operations were created as follows.

TABLE I. MACHINING PROCESS PLAN OF THE PART

\begin{tabular}{|c|c|c|c|c|}
\hline Step No. & Processing Contents and UG-CAM Operation Type & Tool Name and Size[mm] & Spindle Speed[rpm] & Feed Rate[mm/min] \\
\hline 1 & Roughing the first half, Cavity_mill & $\Phi 20$ end mill & 1800 \\
\hline 2 & Semi-finishing the first half, Zlevel_profile & $\Phi 12$ R0.5 bull mill & 3000 \\
\hline 3 & Roughing the second half, Cavity_mill & $\Phi 20$ end mill & 1800 \\
\hline 4 & Semi-finishing the second half, Zlevel_profile & $\Phi 12$ R0.5 bull mill & 3000 \\
\hline 5 & Removing the false boss, Face_milling_area & $\Phi 20$ end mill & 1800 & 500 \\
\hline 6 & Finishing each surface, Face_milling_area & $\Phi 20$ end mill & 3600 & 500 \\
\hline 7 & Engraving numbers on each surface, Contour_text & $\Phi 0.2$ engraving tool & 5000 \\
\hline
\end{tabular}


1) Roughing (of the first half): First of all, the cavity_mill operation type was used to remove the material allowance as soon as possible. The main parameters were set as follows: Cut Pattern-"Follow Part", Stepover-"70\% Tool Diameter", Global Depth per Cut-"2mm", Part Stock-"0.5mm". In order to make the tool engage and retract smooth, Helical Engage/Retract Type was adopted in closed area, and Arc Engage/Retract Type in opening area. The tool path was generated and verified, as shown in Figure V.

2) Semi-finishing (of the first half): In order to leave a uniform part stock and position the workpiece correctly in the finish machining, semi-finish was performed, with the zlevel_profile operation type, Depth per Cut - "0.2mm", and Part Stock-"0.1mm". The simulation machining effect is shown in Figure VI.

3) Finishing: The face-milling-area operation type was used to finishing each surface, with the Cut Pattern-"Zig Zag" and Stepover-" $50 \%$ Tool Diameter".

All the tool paths generated from the operations should be checked, edited, and verified. Once there are some problems, the relevant parameters should be modified to regenerate correct and satisfactory tool paths.
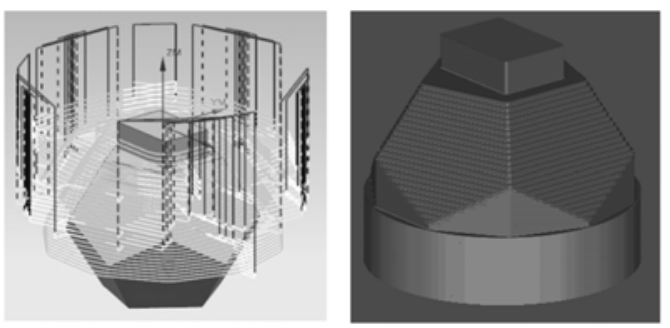

FIGURE V. ROUGHING TOOL PATH AND SIMULATING EFFECT

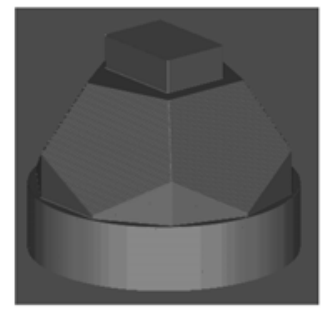

FIGURE VI. SEMI-FINISHING SIMULATING EFFECT

\section{NC Code Generating and Checking}

The postprocessor was customized in accordance with the $\mathrm{CNC}$ milling machine used to machine this part. UG provides a postprocessor builder to do this. Then, in the manufacturing module of UG, the customized postprocessor can be selected to convert tool path file into machine control data (NC code).

To eliminate risk of programming error and prevent gouging and interference, the generated $\mathrm{NC}$ code was further confirmed by using the simulation software YULONG.

\section{PRACTICAL MACHINING}

The NC machining codes were transferred to a 3-axis vertical $\mathrm{CNC}$ milling machine to machine this part and the special fixture. The main procedure of practical machining is shown in Figure VII. Special attention should be paid to the correct installation position of the workpiece when it was turned over and clamped again. Otherwise, some dislocation or mistake will be made.
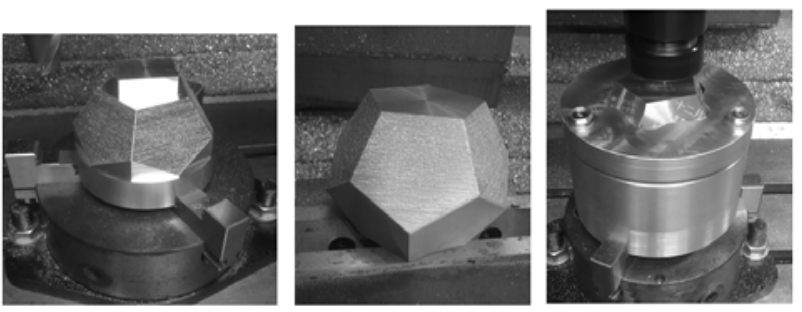

FIGURE VII. THE PHOTO OF PRACTICAL MACHINING PROCEDURE

The finished part is shown in Figure VIII. It has a high shape and dimension accuracy, also good surface quality, meeting all the technical requirements.
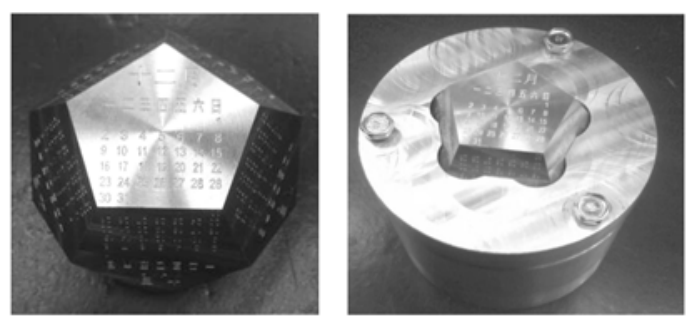

FIGURE VIII. THE REAL PART AND FIXTURE

\section{CONCLUSIONS}

The finished part has a high accuracy and very good surface quality, meeting all the technical requirements. The result shows that the process is reasonable and efficient. The integrated design and manufacture of the part with the special fixture is efficient, due to the powerful CAD/CAM function of UG. The method and technology introduced in this paper can provide valuable reference for similar case, and they are useful for related study.

\section{REFERENCES}

[1] REN Guo-zhu, DONG Xu, and ZHANG Ji-song, "Analysis on CNC Machining Process of Complex and Specialshaped Elliptic Thin-wall Parts, " Coal Mine Machinery, vol. 33, No. 10 (2012), pp. 130-132.

[2] TAO Hua and XU Mingheng, "Development of Special Machining and Post-processing Based on UG,” MACHINE TOOL \& HYDRAULICS, vol. 42, No. 20 (2014), pp. 19-21, 24.

[3] Wang Jianhua, Fan Yongqing, and LiangFeng, "Research on Integrative Numerical Control Machining Technology of Azimuth Bracket Part," Aerospace Manufacturing Technology, No. 2 (2014), pp. 41-44.

[4] Huang Beilei, "Application and Development of CAD/CAM Technology in Modern Industry," China High Technology Enterprises, No. 9 (2011), pp. 59-62.

[5] WANG Lin-feng and BI Chang-fei, "Application and Development of UG," MACHINERY, Vol. 37, No. 7 (2010), pp. 51-54.

[6] Guo Sheng and Yuan Yong-fu, "The Study on CNC Machining and Simulation of the Core with Contoured Surface Based on UG," Machinery Design \& Manufacture, No. 2 (2014), pp. 150-152. 